\title{
Micro-kinetic model of electrochemical carbon dioxide reduction over platinum in non- aqueous solvents
}

Rohr, Brian A.; Singh, Aayush R.; Gauthier, Joseph A.; Statt, Michael J.; Nørskov, Jens K

Published in:

Physical Chemistry Chemical Physics

Link to article, DOI:

$10.1039 / \mathrm{c} 9 \mathrm{cp} 05751 \mathrm{j}$

Publication date:

2020

Document Version

Peer reviewed version

Link back to DTU Orbit

Citation (APA):

Rohr, B. A., Singh, A. R., Gauthier, J. A., Statt, M. J., \& Nørskov, J. K. (2020). Micro-kinetic model of electrochemical carbon dioxide reduction over platinum in non-aqueous solvents. Physical Chemistry Chemical Physics, 22, 9040-9045. https://doi.org/10.1039/c9cp05751j

\section{General rights}

Copyright and moral rights for the publications made accessible in the public portal are retained by the authors and/or other copyright owners and it is a condition of accessing publications that users recognise and abide by the legal requirements associated with these rights.

- Users may download and print one copy of any publication from the public portal for the purpose of private study or research.

- You may not further distribute the material or use it for any profit-making activity or commercial gain

- You may freely distribute the URL identifying the publication in the public portal 


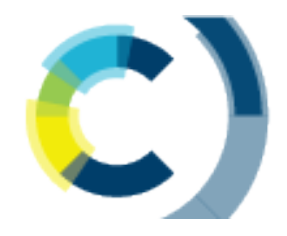

\section{PCCP}

\section{Micro-Kinetic Model of Electrochemical Carbon Dioxide Reduction over Platinum in Non-Aqueous Solvents}

\begin{tabular}{|c|c|}
\hline Journal: & Physical Chemistry Chemical Physics \\
\hline Manuscript ID & CP-ART-10-2019-005751.R2 \\
\hline Article Type: & Paper \\
\hline $\begin{array}{r}\text { Date Submitted by the } \\
\text { Author: }\end{array}$ & 28-Jan-2020 \\
\hline Complete List of Authors: & $\begin{array}{l}\text { Rohr, Brian; Stanford University, Chemical Engineering; Stanford } \\
\text { University } \\
\text { Singh, Aayush; Stanford University, Chemical Engineering } \\
\text { Gauthier, Joseph; Stanford University, Chemical Engineering } \\
\text { Statt, Michale; Stanford University, Chemical Engineering } \\
\text { Nørskov, Jens; Technical University of Denmark, Chemical Engineering }\end{array}$ \\
\hline
\end{tabular}

\section{SCHOLARONE ${ }^{m}$ \\ Manuscripts}


Cite this: DOI: $00.0000 / \operatorname{xxxxxxxxxx}$

Received Date

Accepted Date

DOI: 00.0000/xxxxxxxxxx

\section{Micro-Kinetic Model of Electrochemical Carbon Diox- ide Reduction over Platinum in Non-Aqueous Solvents}

\author{
Brian A. Rohr,$^{\dagger}$ Aayush R. Singh,$^{\dagger}$ Joseph A. Gauthier ${ }^{\dagger}$, Michael J. Statt, ${ }^{\dagger}$ and Jens K. \\ Nørskov**
}

\begin{abstract}
The competition between the hydrogen evolution reaction and the electrochemical reduction of carbon dioxide to multi-carbon products is a well-known challenge. In this study, we present a simple micro-kinetic model of these competing reactions over a platinum catalyst under a strong reducing potential at varying proton concentrations in a non-aqueous solvent. The model provides some insight into the mechanism of reaction and suggests that low proton concentration and a high fraction of stepped sites is likely to improve selectivity to multi-carbon products.
\end{abstract}

\section{Introduction}

Many sources of renewable energy, like wind and solar, are intermittent in nature. Therefore, in order to reduce global carbon dioxide emissions by utilizing such clean energy sources, we must develop technologies for storing energy. There are many ways to store energy, but it is difficult to match the energy density of carbon based fuels. Such fuels would be carbon neutral if they were synthesized using carbon dioxide from the air instead of using natural gas and oil. Additionally, one attractive method of decreasing the chemicals industry's dependence on fossil fuels is to create methods of producing carbon-containing chemicals from carbon dioxide instead of from natural gas and oil. For these reasons, there has been a great deal of effort in developing technologies for electrochemical carbon dioxide reduction.

The competition between hydrogen evolution and carbon dioxide reduction is a significant challenge in the field of electrochemical carbon dioxide reduction. It is well-known that carbon dioxide can be reduced electrochemically to produce carbon monoxide on a gold or silver catalyst at high faradaic efficiency 1 -3. It is also well-known that a variety of reduced carbon products can be produced using a copper catalyst with as little as $20 \%$ of the current lost to hydrogen evolution 4 10. In electrochemical experiments carried out in aqueous solutions, nickel, platinum, palladium, and transition metal catalysts to the left of these metals on the periodic table generally produce primarily hydrogen and very little reduced carbon products. 4

However, there are a few experiments in the literature that demonstrate high faradaic efficiency to reduced carbon products on these strong-binding catalysts in non-aqueous solvents. For

\footnotetext{
†tanford University, Stanford, CA, USA

* Department of Physics, Technical University of Denmark

* Corresponding Author, jkno.dtu.dk
}

example, in a recent study, it was found that reducing the concentration of water in an acetonitrile solution caused the suppression of the hydrogen evolution reaction and therefore increased the faradaic efficiency of carbon dioxide reduction 11 . In another study, Hori et. al. additionally found that decreasing the water concentration favored the production of a two-carbon product over one-carbon products 12 .

In this work, we explore the interesting result presented by Hori et. al. ${ }^{12}$ using a mircokinetic model to better understand the effect of proton donor concentration on the competition between hydrogen evolution and carbon dioxide reduction. We have chosen to model platinum is known as being a great hydrogen evolution catalyst, not a good carbon dioxide reduction catalyst, especially if multi-carbon products are desired, we have chosen to model the reaction on a platinum catalyst

\section{Methods}

In order to generate this micro-kinetic model, it was necessary to determine the adsorption energies of the intermediates. The adsorption energy of $\mathrm{CO}_{2}$ was calculated using density functional theory (DFT). We have chosen to model a platinum surface because we find it worthwhile to explain the very unusual carbon dioxide reduction results that Hori et. al. $\frac{12}{12}$ found on platinum, which normally heavily favors hydrogen evolution over carbon dioxide reduction. The fcc 211 stepped platinum surface was modeled using a unit cell with dimensions $6.90 \AA$ by $8.45 \AA$ by $26.51 \AA$ containing 27 platinum atoms. The bottom two layers were fixed, and the top layer was free to relax. The plane wave cutoff was $600 \mathrm{eV}$, and the density wave cutoff was $6000 \mathrm{eV}$. The ASE-Espresso DFT code $\frac{13}{13}$ with the BEEF exchange correlation functional and the GBRV pseudopotential set were used 14/15/16. The k-point grid was a 4 by 4 by 1 Monkhorst-Pack k-point grid 17 . The electronic energy was converged to $1 \mathrm{e}-5 \mathrm{eV}$, and the forces 
were converged to $0.05 \mathrm{eV} / \mathrm{A}$. Because these were surface calculations, the dipole correction was used in the z-direction. Previously published values for the electronic energies for the carbon dioxide dissociation barrier and the carbon monoxide adsorption energy were used 18119 . For the two adsorption reactions, $\mathrm{CO} 2$ adsorption and $\mathrm{CO}$ adsorption, the change in entropy of the reaction was assumed to be dominated by the loss of gas phase entropy. The entropy of the gas phase species was calculated using DFT to be $0.00188 \mathrm{eV} / \mathrm{K}$. At $298 \mathrm{~K}$, this amounts to a $0.56 \mathrm{eV}$ addition (destabilization) to the $\mathrm{CO} 2$ and $\mathrm{CO}$ adsorption energies. Additionally, due to the strong dipole moment of adsorbed carbon dioxide (since it adopts a bent geometry on the surface), this surface species is stabilized at reducing potentials by interaction with the electric field in the double layer just above the surface. An implicit solvent model was used to calculate the magnitude of this dipole-electric-field interaction, and it was determined to stabilize adsorbed carbon dioxide by $0.2 \mathrm{eV}$ per Volt versus platinum's potential of zero charge. The models have been fit to experimental molecular solvation energies, which they predict quite accurately. Details of these calculations can be found in the supplementary information (SI). The simulated potential in all kinetic models presented was $-2.8 \mathrm{~V}$ vs the computational hydrogen electrode because that is approximately the voltage observed in the experiments carried out by Hori et. al. ${ }^{[12}$ Similar to the standard hydrogen electrode, the potential of the computational hydrogen electrode is the potential at which a proton-electron pair is in equilibrium with $1 / 2 \mathrm{H}_{2}(\mathrm{~g}) .20$ The prefactor for each rate constant was assumed to be $k_{b} T / h$, or $10^{13}$, except for elementary steps that involve solvent reorganization. For these steps, the prefactor was decreased due to a solvent reorganization barrier of $0.2 \mathrm{eV}$, which yields an estimated prefactor of $10^{9} .2122$

\section{Results and Discussion}

\subsection{Kinetic Model}

We present a simple kinetic model that intends to capture the trends shown in the electrochemical carbon dioxide reduction experiment mentioned in the introduction. ${ }^{12}$ The assumptions in this model are very similar to those in previously published work on electrochemical ammonia synthesis in nonaqueous solvents. $\stackrel{23}{2}$ We focus on the following products because they were the ones observed in the experiment: hydrogen, carbon monoxide, formate, and oxalate. Below, a formula unit immediately preceded by a star means that it is adsorbed to the surface

$$
\begin{gathered}
\text { Model I } \\
\mathrm{H}_{2} \mathrm{O}+\mathrm{e}^{-}+* \leftrightarrow{ }^{*} \mathrm{H}+\mathrm{OH}^{-} \\
\mathrm{H}_{2} \mathrm{O}+\mathrm{e}^{-}+{ }^{*} \mathrm{H} \leftrightarrow \mathrm{H}_{2}(\mathrm{~g})+\mathrm{OH}^{-}+* \\
\mathrm{CO}_{2}(\mathrm{~g})+* \leftrightarrow{ }^{*} \mathrm{CO}_{2} \\
\mathrm{H}_{2} \mathrm{O}+2 \mathrm{e}^{-}+{ }^{*} \mathrm{CO}_{2} \leftrightarrow \mathrm{HCOO}^{-}(\mathrm{sol})+\mathrm{OH}^{-}+*
\end{gathered}
$$

$$
\begin{gathered}
2 \mathrm{e}^{-}+2{ }^{*} \mathrm{CO}_{2} \leftrightarrow \mathrm{C}_{2} \mathrm{O}_{4}^{2-}(\mathrm{sol})+2 * \\
{ }^{*} \mathrm{CO}_{2}+* \leftrightarrow{ }^{*} \mathrm{CO}+{ }^{*} \mathrm{O} \\
{ }^{*} \mathrm{CO} \leftrightarrow \mathrm{CO}(\mathrm{g})+* \\
{ }^{*} \mathrm{O}+\mathrm{H}_{2} \mathrm{O}+\mathrm{e}^{-} \leftrightarrow{ }^{*} \mathrm{OH}+\mathrm{OH}^{-} \\
{ }^{*} \mathrm{OH}+\mathrm{H}_{2} \mathrm{O}+\mathrm{e}^{-} \leftrightarrow \mathrm{H}_{2} \mathrm{O}+\mathrm{OH}^{-}+*
\end{gathered}
$$

The experiment was run with a platinum catalyst at strongly reducing potentials (of the order -3V vs SHE), so, all electrochemical steps are assumed to be irreversible and have zero barrier above the solvent reorganization energy, which is taken into account in the prefactor. Since the experiment used a $\mathrm{CO}_{2}$ atmosphere, the partial pressure of $\mathrm{CO}_{2}$ was 1 bar. We assume that the $\mathrm{CO}_{2}$ atmosphere is in equilibrium with the dissolved $\mathrm{CO}_{2}$, and therefore, regardless of the solubility of $\mathrm{CO}_{2}$ in the solvent, the dissolved $\mathrm{CO}_{2}$ has the same chemical potential as 1 bar of $\mathrm{CO}_{2}$ gas. Since the only source of $\mathrm{CO}$ in the experiment was through electrochemical reduction of $\mathrm{CO}_{2}$, a much smaller $\mathrm{CO}$ pressure was assumed (0.01 bar). The adsorption and desorption of carbon monoxide (reaction 7 above) was assumed to be equilibrated. Since we were interested in showing the dependence of C2 selectivity on the C-C coupling rate constant and the water concentration, those two parameters were independent variables in this study.

\subsection{Comparison to Experiment}

The mean-field, steady-state kinetic model was solved under the assumptions above for a range of values of water concentration and C-C coupling barrier. The only free parameter in the model is the $\mathrm{C}$-C coupling barrier. This was done for several reasons. First, it is difficult to determine this particular C-C coupling barrier computationally because the initial state, the transition state, and especially the final state depend heavily on the solvent for their stability. Determining the relevant solvent structure, or more accurately, a representative ensemble of relevant solvent structures for a variety of water-acetonitrile mixtures near a surface with an applied potential would be a difficult study by itself, and calculating the transition state energy as electrons are transferred from the surface to the solvent would also be a difficult study in and of itself. The other relevant adsorption energies and barriers in this model are much easier to estimate, so they were not treated as free variables. Second, even on a platinum surface, there are a wide variety of factors that influence the magnitude of this barrier. The applied potential, which ions are present in the solvent, and which facets are present may all have an impact on the magnitude of this barrier. By allowing the magnitude of the C-C coupling barrier to be a free parameter, we illustrate how the selectivity to each product changes as a function of the magnitude of this variable. This may help future researchers understand to what degree the C-C coupling barrier must be changed in order 


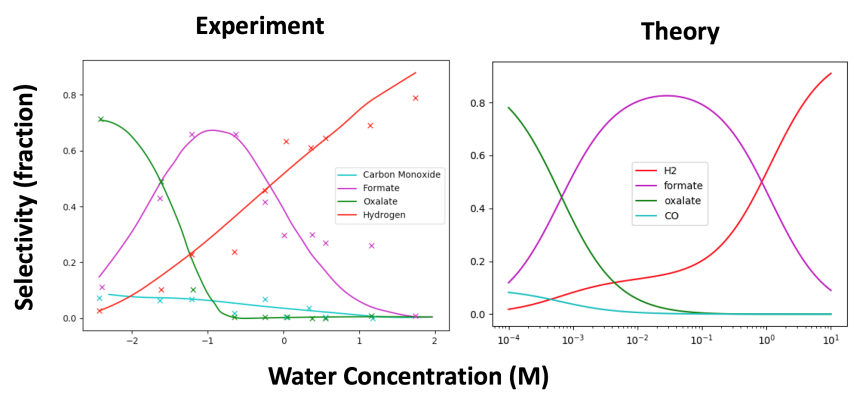

Fig. 1 Comparison of experimental data taken from Hori et. al (left) 12 and the results of the theoretical kinetic model. The experiments were run over a platinum catalyst in acetonitrile with varying concentrations of water. Both plots show the selectivity to each of the four species observed in the Hori experiment ${ }^{112}$ as a function of the log of the water concentration. In this figure, the C-C coupling rate constant is $1.7 \cdot 10^{6} \mathrm{~s}^{-1}$, which was chosen to fit the experimental data.

to have a meaningful impact on the selectivity. Carrying out the study in this way is a good fit for theoretical modeling because it provides information that is very difficult to access with physical experiments; carrying out the same study experimentally would be nearly impossible due to the difficulty of isolating this variable. Using the C-C coupling barrier that best matched the experiment, the results of the kinetic model are shown below.

At this value for the C-C coupling rate constant, there is good agreement between the simple kinetic model and the experimental results observed. Even though one value was fit to experimental data, it is only possible to show good agreement between data and a mathematical model with one fit parameter if the functional form of the mathematical model is correct. The fact that there is good agreement between the experimental selectivity data and the selectivity curves generated using kinetic Model I provides some evidence that the equations that produce the selectivity curves are physically relevant. Since these equations are derived directly from the kinetic model, this provides some evidence that kinetic Model I is physically relevant. In both cases, the selectivity to hydrogen is high when water is abundant. As the water concentration is decreased, the major product shifts to formate, and finally, at very low water concentration, the primary product becomes oxalate. Carbon monoxide is only seen in small amounts and only when the water concentration is very low.

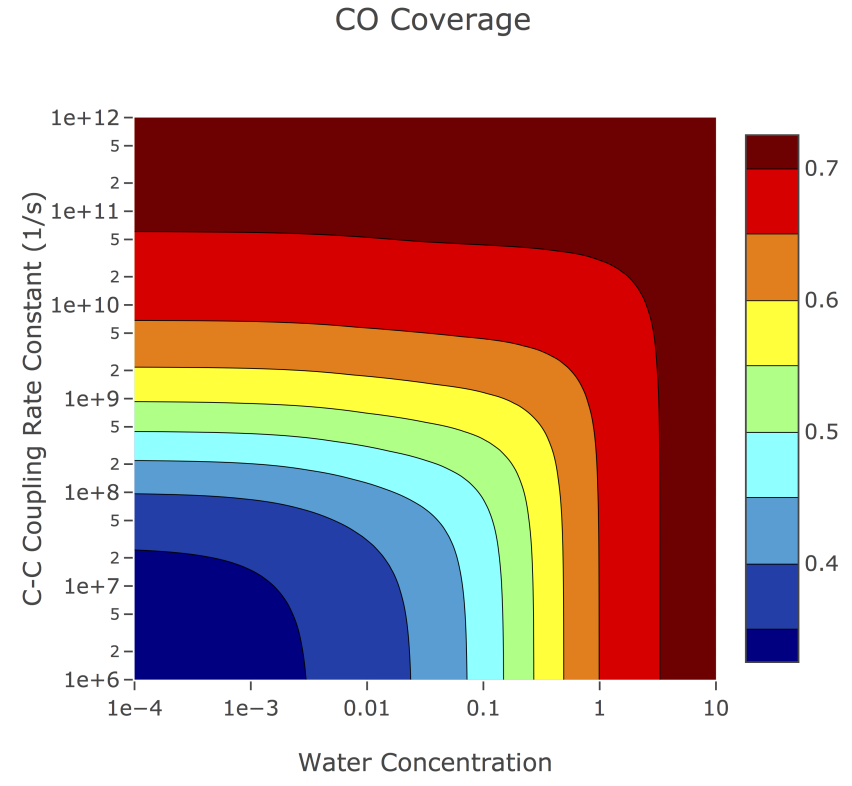

Fig. 2 Model l's estimate of the coverage of surface-bound carbon monoxide as a function of water concentration and the $\mathrm{C}-\mathrm{C}$ coupling rate constant.

As shown in Figure 2. * $\mathrm{CO}$ is one of the dominant surface species under all conditions in this study (note that the color bar in Figure 2 ranges from $40 \%-70 \%$ ). This is in agreement with Hori's experimental results, which showed the presence of *CO using Fourier transform infrared reflection absorption spectroscopy (FT-IRRAS), 12. The results from the Model I are in good agreement with experiment regarding the surface coverage as well. Figures $1-5$ in the supplementary information show the coverage of each of the other surface species under a wide range of water concentrations and C-C coupling rate constants. This agreement between Model I and the experiment with respect to both the selectivity of each product and the surface coverage suggests that the simple kinetic model is able to qualitatively capture the trends observed in the experiment.

\subsection{Mechanistic Insights}

We can draw some insights into the mechanism of the reaction by analyzing a variant of the kinetic model presented in Equations 1 -9. In the previously presented kinetic model, the mechanism for carbon monoxide evolution is modeled as the dissociation ${ }^{*} \mathrm{CO}_{2}$ followed by electrochemical reduction of ${ }^{*} \mathrm{O}$ to $\mathrm{H}_{2} \mathrm{O}$ via the ${ }^{*} \mathrm{OH}$ intermediate. In contrast, in the kinetic model presented below, the mechanism for carbon monoxide evolution is modeled as the direct electrochemical reduction of ${ }^{*} \mathrm{CO}_{2}$ to $\mathrm{CO}$ and $\mathrm{H}_{2} \mathrm{O}$ via a ${ }^{*} \mathrm{COOH}$ intermediate. Again, below, a formula unit immediately preceded by a star means that it is adsorbed to the surface.

\section{Model II}

$$
\mathrm{H}_{2} \mathrm{O}+\mathrm{e}^{-}+* \leftrightarrow{ }^{*} \mathrm{H}+\mathrm{OH}^{-}
$$




$$
\begin{gathered}
\mathrm{H}_{2} \mathrm{O}+\mathrm{e}^{-}+{ }^{*} \mathrm{H} \leftrightarrow \mathrm{H}_{2}(\mathrm{~g})+\mathrm{OH}^{-}+* \\
\mathrm{CO}_{2}(\mathrm{~g})+* \leftrightarrow{ }^{*} \mathrm{CO}_{2} \\
\mathrm{H}_{2} \mathrm{O}+2 \mathrm{e}^{-}+{ }^{*} \mathrm{CO}_{2} \leftrightarrow \mathrm{HCOO}^{-}(\mathrm{sol})+\mathrm{OH}^{-}+* \\
2 \mathrm{e}^{-}+2^{*} \mathrm{CO}_{2} \leftrightarrow \mathrm{C}_{2} \mathrm{O}_{4}^{2-}(\mathrm{sol})+2 * \\
{ }^{*} \mathrm{CO}_{2}+\mathrm{H}_{2} \mathrm{O}+\mathrm{e}^{-} \leftrightarrow{ }^{*} \mathrm{COOH}+\mathrm{OH}^{-}
\end{gathered}
$$$$
{ }^{*} \mathrm{COOH}+\mathrm{H}_{2} \mathrm{O}+\mathrm{e}^{-} \leftrightarrow \mathrm{CO}(\mathrm{g})+\mathrm{H}_{2} \mathrm{O}+\mathrm{OH}^{-}+*
$$

When this steady state kinetic model is solved under the same assumptions, the expression for the ratio of the rate of carbon monoxide production to the rate of formate production is given by the following expression:

$$
\frac{r_{C O}}{r_{\text {formate }}}=\frac{k_{15} \theta_{\mathrm{CO}_{2} c_{+}}}{k_{13} \theta_{\mathrm{CO}_{2}} c_{+}}=\frac{k_{15}}{k_{13}}
$$

This expression shows that, if the mechanism presented in Equations 10 - 16 were correct, the rate of carbon monoxide production would be a constant multiple of the rate of formate production. Since equations 13 and 15 are both proton-electron transfers to oxygen, we do not expect the ratio of the two to have a strong dependence on water concentration. Solving the kinetic model at many values of water concentration yields the plot below.

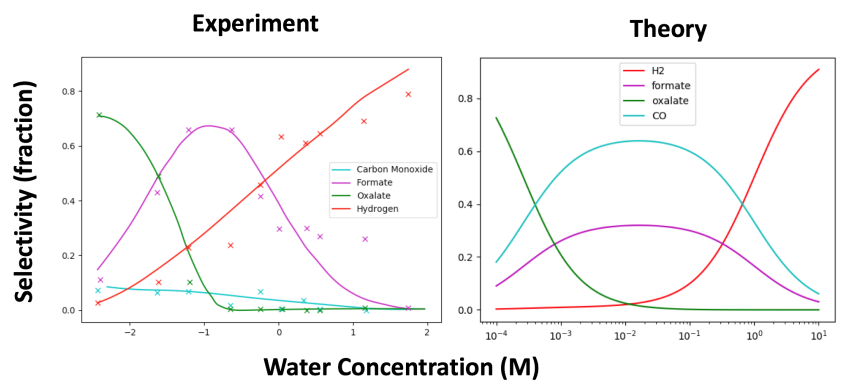

Fig. 3 Comparison of experimental data taken from Hori et. al (left) and the results of the updated theoretical kinetic model with an allelectrochemical mechanism for $\mathrm{CO}$ evolution 12 . Both plots show the selectivity to each of the four species observed in the Hori experiment as a function of the log of the water concentration. In this figure, the rate constant for $\mathrm{CO}$ production was altered so that it can be distinguished from the formate curve.

In the experiment, as the water concentration becomes very low, the selectivity to formate decreases while the selectivity to carbon monoxide increases, whereas in Model II, the selectivity to carbon monoxide is a constant multiple of the selectivity to formate, so it is impossible for one to increase while the other decreases. It is clear that, regardless of the values of $\mathrm{k}_{1} 3$ and
Oxalate Selectivity

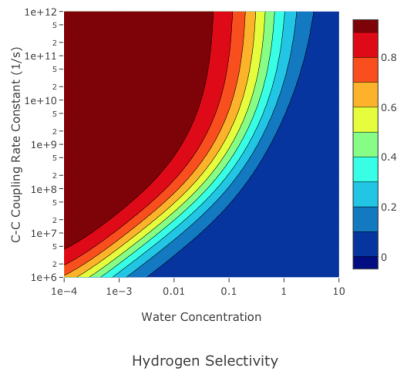

Hydrogen Selectivity

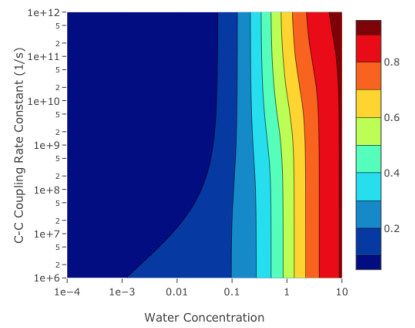

Formate Selectivity

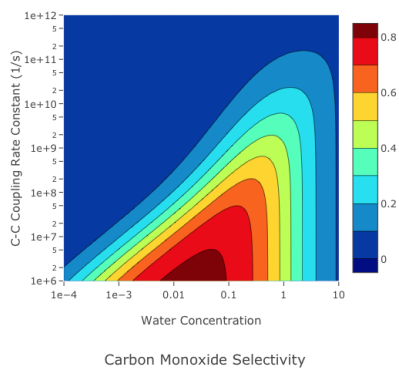

Carbon Monoxide Selectivity

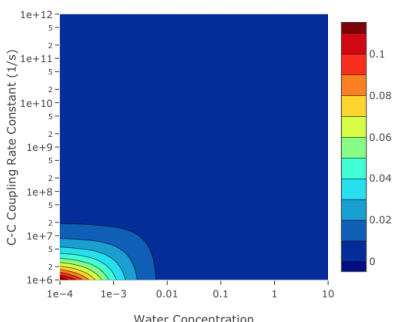

Water Concentration
Fig. 4 Selectivity to each of the four products observed in the Hori experiment ${ }^{12}$ as a function of the water concentration (log scale) and the C-C coupling rate constant.

$\mathrm{k}_{1} 5$, the experimentally observed result cannot be reproduced using this all-electrochemical carbon monoxide production model. The fact that kinetic Model II cannot simulate the experimental data provides evidence that the reaction does not proceed exlusively through this pathway. In other words, this suggests that the mechanism of carbon dioxide reduction to carbon monoxide on strong-binding catalysts like platinum includes a thermochemical step.

\subsection{Effect of C-C Coupling Barrier and Water Concentration}

Using Model I (Equations 1 -9), the selectivity of each of the four products can be calculated over a wide range of water concentrations and C-C coupling barriers, as shown in Figure 4 From these contour plots, we can see that selectivity to oxalate, the C2 product is improved by decreasing water concentration or by decreasing the $\mathrm{C}-\mathrm{C}$ coupling barrier, and therefore increasing the C-C coupling rate constant. We can also see that if formate were the desired product, it would be ideal to have a catalyst with a high $\mathrm{C}-\mathrm{C}$ coupling rate constant. Furthermore, the model shows that $\mathrm{CO}$ production is very difficult on platinum. The selectivity to $\mathrm{CO}$ is very low throughout this wide range of water concentrations and C-C coupling rate constant. This is consistent with the well-known fact that platinum is far too strong-binding for carbon monoxide desorption to occur at a high rate at $300 \mathrm{~K}$; gold is the best known catalyst. Lastly, the model shows that, regardless of the C-C coupling constant, the selectivity to hydrogen evolution will be very high if protons are readily available. This suggests that finding a catalyst with high C2 selectivity in pure water may be very difficult. 


\subsection{Strategies for Improving C2 Selectivity}

Solving the steady-state kinetic model in Equations 1 - 9 analytically for the ratio of the rate of the $\mathrm{C} 2$ product (oxalate) to the rate of the $\mathrm{C} 1$ product (formate) further clarifies two strategies for increasing selectivity to the $\mathrm{C} 2$ product. The resulting expression is below.

$$
\frac{r_{\text {oxalate }}}{r_{\text {formate }}}=\frac{k_{5} \theta_{\mathrm{CO}_{2}}}{k_{4} c_{+}}
$$

In this equation, the subscripted numbers refer to the equation number in the micro-kinetic model I. The C-C coupling rate constant is $\mathrm{k}_{5}$, and the proton transfer to produce formate is $\mathrm{k}_{4}$. The concentration of water is $c_{+}$(as it is the proton donor), and the coverage of $\mathrm{CO}_{2}$ is $\theta_{\mathrm{CO}_{2}}$. This expression suggests that there are four ways to improve $\mathrm{C} 2$ selectivity, in principle: increase $\mathrm{k}_{5}$, increase $\theta_{\mathrm{CO}_{2}}$, decrease $\mathrm{k}_{4}$, or decrease $c_{+}$. However, our model (see Figure 2 in the supplementary information) shows that $\theta_{\mathrm{CO}_{2}}$ never exceeds about $7 \%$ within the range of water concentrations and C-C coupling barriers explored in this study. We do not see any obvious way to increase $\theta_{\mathrm{CO}_{2}}$. ${ }^{*} \mathrm{CO}$ is a substantially more stable surface-bound species than ${ }^{*} \mathrm{CO}_{2}$, so we do not expect $* \mathrm{CO}_{2}$ to be the dominant surface-bound species unless the dissociation of $* \mathrm{CO}_{2}$ were kinetically hindered, which would be difficult to achieve. The barrier that governs the value of $\mathrm{k}_{4}$ is electrochemical, and at the strong reducing potentials studied here, it may be difficult to decrease $\mathrm{k}_{4}$. However, decreasing $\mathrm{c}_{+}$ is straightforward in principle; this study and the experimental data shown in section 3.2 suggest that higher selectivity to C2 products can be achieved limiting access to protons at the cathode. This is in agreement with several other experimental findings $1124 \mid 25$. Lastly, it is possible to change $\mathrm{k}_{5}$ by changing the catalyst structure. Previous theoretical work shows that stepped sites have much lower C-C coupling barriers than terrace sites, as shown in Figure 5. This suggests that catalysts with a higher concentration of stepped sites will have higher C2 selectivity. This is also in agreement with several experimental results 26 . This further suggests a promising research direction for computational chemists; according to this model, finding a catalyst geometry with more favorable $\mathrm{C}-\mathrm{C}$ coupling transition state energies would be a valuable addition to the effort to increase selectivity to C2 products in electrochemical carbon dioxide reduction.

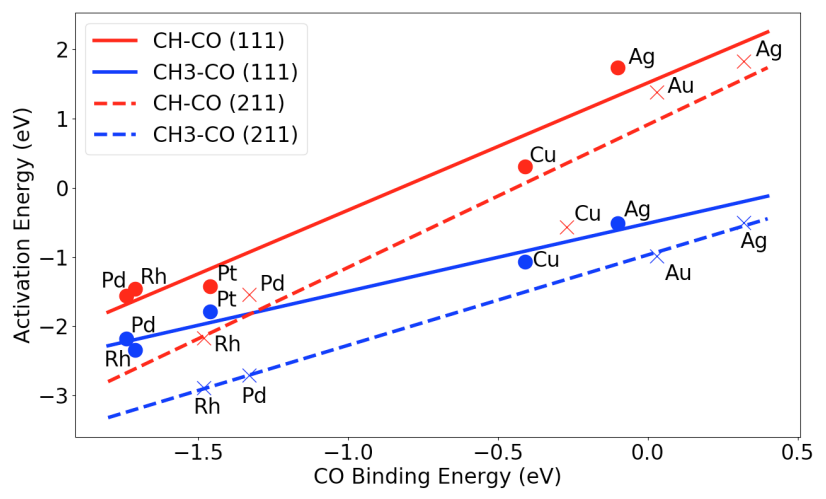

Fig. 5 Plot of the activation electronic energy for the $\mathrm{C}-\mathrm{C}$ coupling surface reaction for two multi-carbon surface intermediates $(\mathrm{CH}-\mathrm{CO}$ and $\mathrm{CH} 3-$ $\mathrm{CO})$ vs. the $\mathrm{CO}$ binding electronic energy on the fcc metal steps (211 facet) and fcc metal terraces (111 facet). The dashed lines fall below the solid lines, indicating that $\mathrm{C}-\mathrm{C}$ coupling is more facile on steps than terraces. Unlike the ${ }^{*} \mathrm{CO}_{2}{ }^{-}{ }^{*} \mathrm{CO}_{2}$ coupling barrier, these $\mathrm{C}-\mathrm{C}$ coupling barriers are straightforward to calculate because the initial, final, and transition states do not depend on the solvent for their stability, and a vacuum DFT model provides useful information.

\section{Conclusions}

We present a simple kinetic model for carbon dioxide reduction on strong-binding catalysts at strong reducing potentials that agrees qualitatively with observed experimental data. Though simple, the model is able to provide useful insights. First, the model suggests that the mechanism for carbon monoxide evolution includes a thermochemical step. Additionally, the model suggests that stepped surfaces and other catalyst geometries with favorable $\mathrm{C}$-C coupling barriers should yield higher selectivity to $\mathrm{C}_{2}$ products.

\section{Acknowledgements}

The authors would like to thank the Villum Center for the Science of Sustainable Fuels and Chemicals and the U.S. Department of Energy Office of Basic Energy Sciences for supporting this work. Additionally, the authors would like to thank the U.S. NSF GFRP program, grant number DGE-1656518, for supporting B.A.R.

\section{Notes and references}

1 W. Zhu, R. Michalsky, Ö. Metin, H. Lv, S. Guo, C. J. Wright, X. Sun, A. A. Peterson and S. Sun, Journal of the American Chemical Society, 2013, 135, 16833-16836.

2 Y. Chen, C. W. Li and M. W. Kanan, Journal of the American Chemical Society, 2012, 134, 19969-19972.

3 R. G. Mariano, K. McKelvey, H. S. White and M. W. Kanan, Science, 2017, 358, 1187-1192.

4 Y. Hori, H. Wakebe, T. Tsukamoto and O. Koga, Electrochimica Acta, 1994, 39, 1833 - 1839.

5 M. Gattrell, N. Gupta and A. Co, Journal of Electroanalytical Chemistry, 2006, 594, 1-19.

6 M. Le, M. Ren, Z. Zhang, P. T. Sprunger, R. L. Kurtz and J. C. Flake, Journal of The Electrochemical Society, 2011, 158, E45E49.

7 A. Loiudice, P. Lobaccaro, E. A. Kamali, T. Thao, B. H. Huang, 
J. W. Ager and R. Buonsanti, Angewandte Chemie International Edition, 2016, 55, 5789-5792.

8 S. Sen, D. Liu and G. T. R. Palmore, ACS Catalysis, 2014, 4, 3091-3095.

9 Y. Song, R. Peng, D. K. Hensley, P. V. Bonnesen, L. Liang, Z. Wu, H. M. Meyer III, M. Chi, C. Ma, B. G. Sumpter and A. J. Rondinone, ChemistrySelect, 2016, 1, 6055-6061.

10 Y. Hori, in Electrochemical CO2 Reduction on Metal Electrodes, ed. C. G. Vayenas, R. E. White and M. E. Gamboa-Aldeco, Springer New York, New York, NY, 2008, pp. 89-189.

11 S. Piontek, K. junge Puring, D. Siegmund, M. Smialkowski, I. Sinev, D. Tetzlaff, B. Roldan Cuenya and U.-P. Apfel, Chem. Sci., 2019, 10, 1075-1081.

12 Y. Tomita and Y. Hori, Advances in Chemical Conversions for Mitigating Carbon Dioxide, Elsevier, 1998, vol. 114, pp. 581 584.

13 P. Giannozzi, S. Baroni, N. Bonini, M. Calandra, R. Car, C. Cavazzoni, D. Ceresoli, G. L. Chiarotti, M. Cococcioni, I. Dabo, A. D. Corso, S. de Gironcoli, S. Fabris, G. Fratesi, R. Gebauer, U. Gerstmann, C. Gougoussis, A. Kokalj, M. Lazzeri, L. Martin-Samos, N. Marzari, F. Mauri, R. Mazzarello, S. Paolini, A. Pasquarello, L. Paulatto, C. Sbraccia, S. Scandolo, G. Sclauzero, A. P. Seitsonen, A. Smogunov, P. Umari and R. M. Wentzcovitch, Journal of Physics: Condensed Matter, 2009, 21, 395502.

14 S. R. Bahn and K. W. Jacobsen, Comput. Sci. Eng., 2002, 4, 56-66.

15 J. Wellendorff, K. T. Lundgaard, A. Møgelhøj, V. Petzold, D. D. Landis, J. K. Nørskov, T. Bligaard and K. W. Jacobsen, Phys. Rev. B, 2012, 85, 1-23.

16 B. J. W. R. K. M. Garrity, Kevin F. and D. Vanderbilt, Computational Materials Science, 2014, 81, 446-452.

17 H. J. Monkhorst and J. D. Pack, Phys. Rev. B, 1976, 13, 51885192.

18 H. Falsig, B. Hvolbæk, I. Kristensen, T. Jiang, T. Bligaard, C. Christensen and J. Nørskov, Angewandte Chemie International Edition, 2008, 47, 4835-4839.

19 M. J. Hoffmann, A. J. Medford and T. Bligaard, The Journal of Physical Chemistry C, 2016, 120, 13087-13094.

20 J. K. Nørskov, J. Rossmeisl, A. Logadottir, L. Lindqvist, J. R. Kitchin, T. Bligaard and H. Jónsson, The Journal of Physical Chemistry B, 2004, 108, 17886-17892.

21 D. T. Limmer, A. P. Willard, P. Madden and D. Chandler, Proceedings of the National Academy of Sciences, 2013, 110, 42004205.

22 H. A. Hansen, V. Viswanathan and J. K. Nørskov, The Journal of Physical Chemistry C, 2014, 118, 6706-6718.

23 A. R. Singh, B. A. Rohr, M. J. Statt, J. A. Schwalbe, M. Cargnello and J. K. Nørskov, ACS Catalysis, 2019, 9, 83168324.

24 K. Ito, S. Ikeda, N. Yamauchi, T. Iida and T. Takagi, Bulletin of the Chemical Society of Japan, 1985, 58, 3027-3028.

25 M. Ma, K. Djanashvili and W. A. Smith, Angewandte Chemie International Edition, 2016, 55, 6680-6684.
26 M. G. Kibria, C.-T. Dinh, A. Seifitokaldani, P. De Luna, T. Burdyny, R. Quintero-Bermudez, M. B. Ross, O. S. Bushuyev, F. P. García de Arquer, P. Yang, D. Sinton and E. H. Sargent, Advanced Materials, 30, 1804867.

27 Q. Fan, M. Zhang, M. Jia, S. Liu, J. Qiu and Z. Sun, Materials Today Energy, 2018, 10, 280-301.

28 Y. Hori, I. Takahashi, O. Koga and N. Hoshi, Journal of Molecular Catalysis A: Chemical, 2003, 199, 39-47. 


\title{
Supplementary Information for: Micro-Kinetic Model of Electrochemical Carbon Dioxide Reduction over Platinum in Non-Aqueous Solvents
}

\author{
Brian A. Rohr, ${ }^{a}$ Aayush R. Singh, ${ }^{a}$ Joseph A. Gauthier, ${ }^{a}$ Michael J. Statt, ${ }^{a}$ and Jens K. Nørskov ${ }^{b, *}$
}

\section{Details of Implicit Solvation Model for Po- tential Dependence of $\mathrm{CO}_{2}$ Adsorption}

To determine the potential dependence of $\mathrm{CO}_{2}$ adsorption, grandcanonical constant potential calculations were performed. The Vienna Ab-Initio Simulation Package ${ }^{1-3}$ was used, with the electrolyte modeled by the polarizable continuum model as implemented in VASPsol. ${ }^{45}$ The counter-charge was modeled with the linearized Poisson-Boltzmann equation with a Debye screening length of 3 , corresponding to $1.0 \mathrm{M}$ electrolyte. Further details of the polarizable continuum can be found in its documentation. 45 To counteract the substantial dipole moment of adsorbed $\mathrm{CO}_{2}$ (which adopts a bent configuration), charge and countercharge is introduced to obtain constant potential energetics. The potential dependence of $\mathrm{CO}_{2}$ adsorption depends proportionally to the strength of this dipole moment, which is largely independent of the metal it binds to and rather depends on the configuration of the $\mathrm{CO}_{2}$ molecule. On Pt (111), this potential dependence was calculated to be $0.2 \mathrm{eV}$ of stabilization per Volt of potential, with $\mathrm{CO}_{2}$ being stabilized by more reducing potentials.

\footnotetext{
${ }^{a}$ Stanford University, Stanford, CA, USA

${ }^{b}$ Department of Physics, Technical University of Denmark

${ }^{*}$ Corresponding Author, jkno.dtu.dk
} 


\section{Coverage Heatmaps}

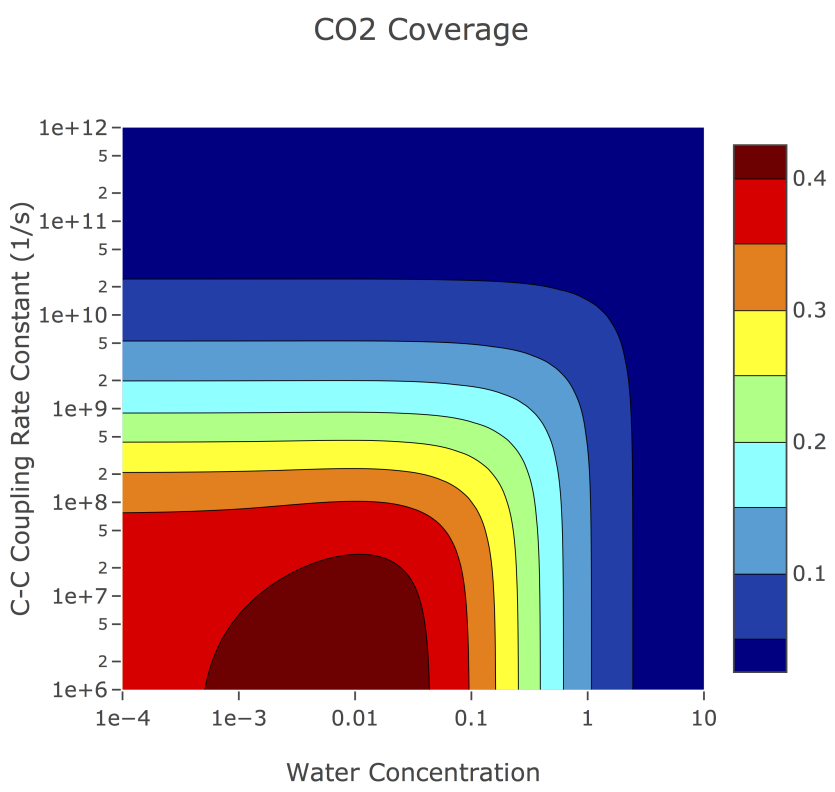

Fig. 1 Model l's estimate of the coverage of surface-bound carbon dioxide as a function of water concentration and the $\mathrm{C}-\mathrm{C}$ coupling rate constant.

\section{O Coverage}

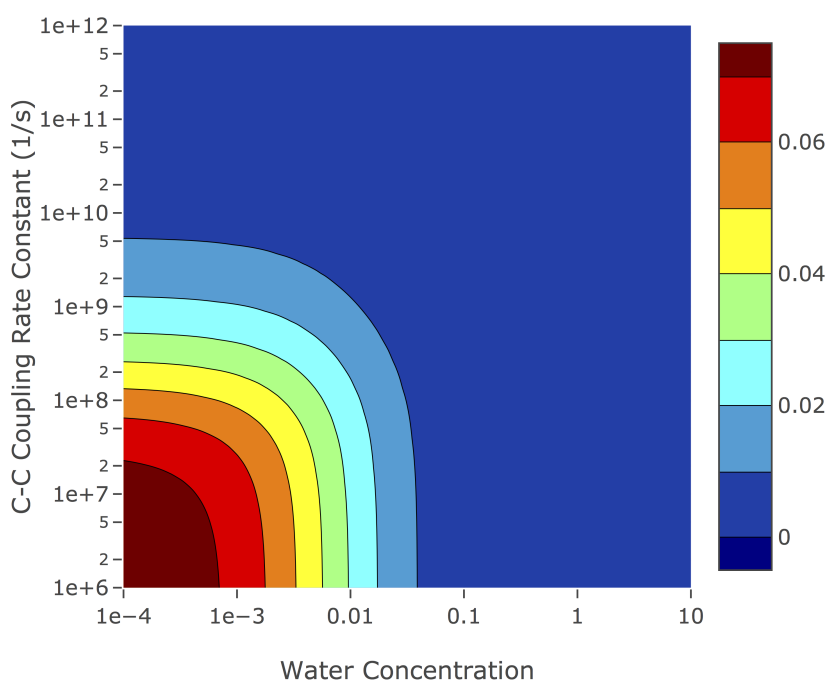

Fig. 2 Model l's estimate of the coverage of surface-bound oxygen as a function of water concentration and the $\mathrm{C}-\mathrm{C}$ coupling rate constant.

\section{$\mathrm{OH}$ Coverage}

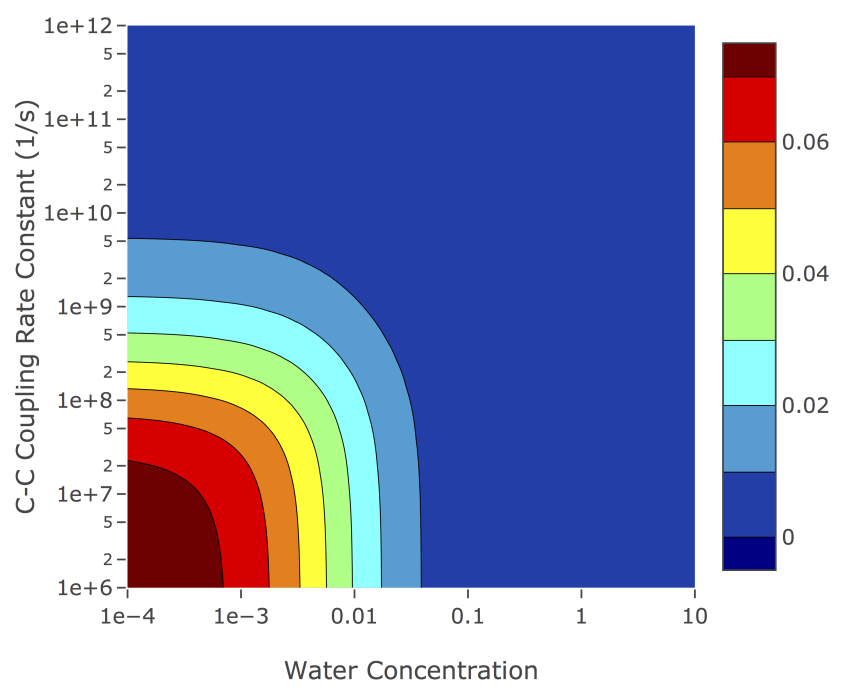

Fig. 3 Model l's estimate of the coverage of surface-bound $\mathrm{OH}$ as a function of water concentration and the $\mathrm{C}-\mathrm{C}$ coupling rate constant.

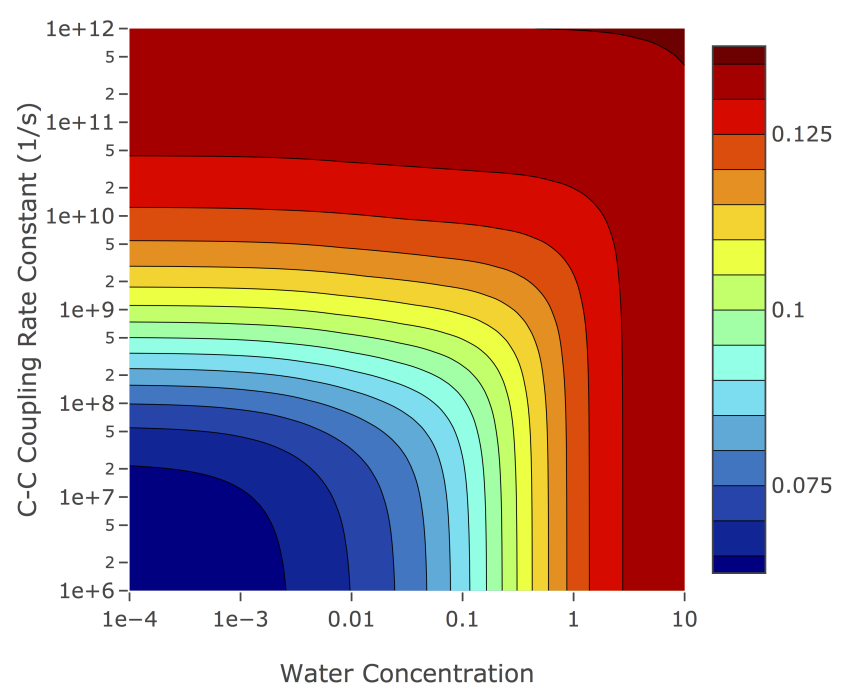

Fig. 4 Model l's estimate of the coverage of surface-bound hydrogen as a function of water concentration and the $\mathrm{C}-\mathrm{C}$ coupling rate constant. 


\section{Empty Site Coverage}

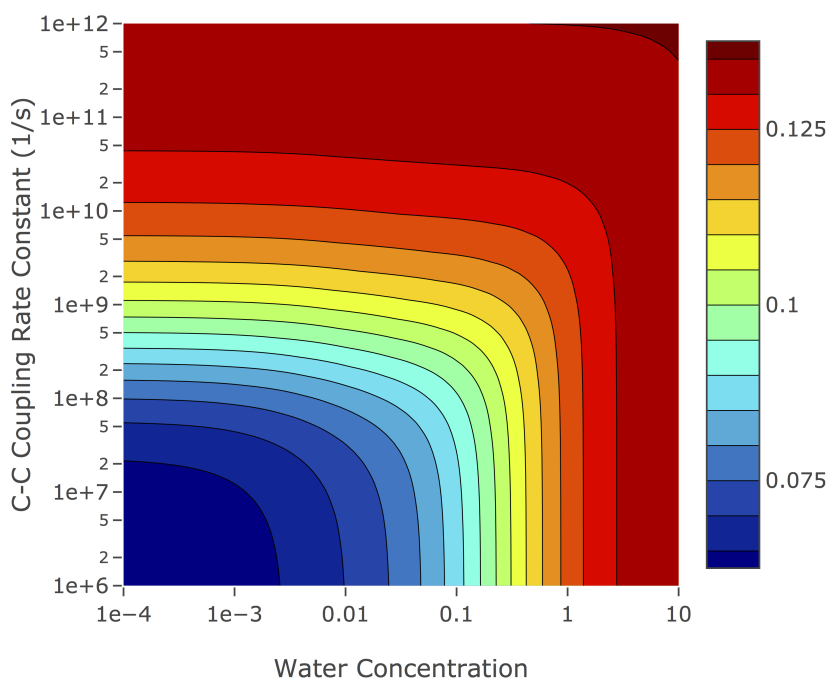

Fig. 5 Model l's estimate of the coverage of empty sites as a function of water concentration and the $\mathrm{C}-\mathrm{C}$ coupling rate constant.

\section{Notes and references}

1 G. Kresse and J. Furthmüller, Physical Review B, 1996, 54, 11169-11186.

2 G. Kresse and J. Furthmüller, Computational Materials Science, 1996, 6, 15-50.

3 G. Kresse and J. Hafner, Physical Review B, 1993, 47, 558-561.

4 K. Mathew, R. Sundararaman, K. Letchworth-Weaver, T. Arias and R. G. Hennig, The Journal of Chemical Physics, 2014, 140, 084106.

5 K. Mathew and R. G. Hennig, arXiv preprint arXiv:1601.03346, 2016. 